Article

\title{
Transcriptional Signatures of Immune, Neural, and Endocrine Functions in the Brain and Kidney of Rainbow Trout (Oncorhynchus mykiss) in Response to Aeromonas salmonicida Infection
}

\author{
Mengqun Liu, Xiaodong Yang, Chu Zeng, Hongkui Zhao, Jifang Li, Zhishuai Hou * and Haishen Wen *
}

check for

Citation: Liu, M.; Yang, X.; Zeng, C.; Zhao, H.; Li, J.; Hou, Z.; Wen, H. Transcriptional Signatures of Immune, Neural, and Endocrine Functions in the Brain and Kidney of Rainbow Trout (Oncorhynchus mykiss) in Response to Aeromonas salmonicida Infection. Int. J. Mol. Sci. 2022, 23, 1340. https://doi.org/10.3390/ ijms 23031340

Academic Editor: Alberto Cuesta

Received: 22 December 2021

Accepted: 21 January 2022

Published: 25 January 2022

Publisher's Note: MDPI stays neutral with regard to jurisdictional claims in published maps and institutional affiliations.

Copyright: (C) 2022 by the authors. Licensee MDPI, Basel, Switzerland. This article is an open access article distributed under the terms and conditions of the Creative Commons Attribution (CC BY) license (https:// creativecommons.org/licenses/by/ $4.0 /)$

\begin{abstract}
Key Laboratory of Mariculture, Ministry of Education (KLMME), Ocean University of China, Qingdao 266003, China; liumengqun0826@126.com (M.L.); yxd19951108@163.com (X.Y.); zengchu1234@126.com (C.Z.); zhaohongkuiouc@163.com (H.Z.); lijf@ouc.edu.cn (J.L.)

* Correspondence: zzh0024@auburn.edu (Z.H.); wenhaishen@ouc.edu.cn (H.W.); Tel.: +86-133-4524-7715 (Z.H.); $+86-532-8203-1825$ (H.W.)
\end{abstract}

\begin{abstract}
Rainbow trout (Oncorhynchus mykiss) serves as one of the most important commercial fish with an annual production of around 800,000 tonnes. However, infectious diseases, such as furunculosis caused by Aeromonas salmonicida infection, results in great economic loss in trout culture. The brain and kidney are two important organs associated with "sickness behaviors" and immunomodulation in response to disease. Therefore, we worked with 60 trout and investigated transcriptional responses and enrichment pathways between healthy and infected trout. We observed that furunculosis resulted in the activation of toll-like receptors with neuroinflammation and neural dysfunction in the brain, which might cause the "sickness behaviors" of infected trout including anorexia and lethargy. We also showed the salmonid-specific whole genome duplication contributed to duplicated colony stimulating factor 1 (csf-1) paralogs, which play an important role in modulating brain immunomodulation. Enrichment analyses of kidneys showed up-regulated immunomodulation and down-regulated neural functions, suggesting an immune-neural interaction between the brain and kidney. Moreover, the kidney endocrine network was activated in response to $A$. salmonicida infection, further convincing the communications between endocrine and immune systems in regulating internal homeostasis. Our study provided a foundation for pathophysiological responses of the brain and kidney in response to furunculosis and potentially offered a reference for generating disease-resistant trout strains.
\end{abstract}

Keywords: rainbow trout; Aeromonas salmonicida; furunculosis; immunomodulation; RNA-Seq

\section{Introduction}

Fish serves as an important single source of high-quality protein [1]. Based on the statement of the Food and Agriculture Organization (FAO) of the United Nations, fish consists of around 16\% of animal protein consummation worldwide (FAO, 1997; [1]). Due to the global decline of ocean fishery stocks, a Nature paper indicated that aquaculture might act as a solution for increased fishery production [2]. For example, aquaculture produced more than 80 million tonnes of fish and shellfish in 2017, providing protein-rich food to consumers from low- to high-income regions (FAO, 2019; [3-7]). Rainbow trout (Oncorhynchus mykiss) is one of the most important commercial and market fish with global production around 800 thousand tonnes (FAO, 2020). Compared to dramatically depleted wild fishery resources, cultured fish are making up an increasing proportion of the world's fishery population [1].

The cultured fish must cope with multiple environmental and pathogen challenges [8,9]. Moreover, the environmental stimuli might result in the stress of fish, thus causing increased susceptibility of disease with pathogen load $[10,11]$. The bacterium Aeromonas salmonicida 
(Aeromonas salmonicida. A. salmonicida subsp. salmonicida), which has been identified as one of the most infective and lethal pathogens for over 100 years, acts as the causative agent of furunculosis [12-14]. Furunculosis derives its name from the development of furuncles (boils) on the skin [15]. After infection, A. salmonicida could enter the host cells of skin, gills, and intestines, and then rapidly infect the internal organs, thus resulting in severe symptoms and mortality of the infected individuals [16,17]. The A. salmonicida is reported to result in diseases in a wide range of freshwater fish, including salmonids, common carp (Cyprinus carpio), European catfish (Silurus glanis), Cottus gobio and fathead minnow (Pimephales promelas), and the seawater species of turbot (Scophthalmus maximus), and sea bream (Sparus aurata) $[18,19]$. Fish infected by A. salmonicida exhibit high morbidity, severe symptoms, and high mortality, thus resulting in great economic loss [12].

The characteristics, virulence, and genome of $A$. salmonicida has been thoroughly investigated, as well as the symptoms, pathophysiology, and pathology [20-24]. For example, in physiological levels, the fish infected by A. salmonicida exhibits the symptoms of anorexia, lethargy, abnormal swimming behavior, and haemorrhagic septicaemia with darkened skin pigmentation, skin ulcers and necrosis, and internal bleeding [20,23,25,26]. On the molecular level, several studies revealed the molecular mechanisms of immunomodulation and inflammation in response to $A$. salmonicida infection, including the expression profiles of cytokines, signaling pathways of toll-like receptors, and activation and migration of immune cells [27-31]. A recent study further confirmed that infection of $A$. salmonicida not only impairs the cell physiology and phagocytosis of trout, but also severely dysregulates gene transcription of immune mediators and disturbs the warning signals related to infection recognition and immunomodulation [32]. In recent decades, the omics analyses provide a big database showing the genes, proteins, and metabolites associated with $A$. salmonicida infection [21,33-36]. For example, a transcriptome analysis showed an important splenic mciroRNA (miR-155-5p) which is associated with inflammation caused by A. salmonicida infection [22]. A recent proteomic analysis revealed kidney HADH ( $\beta$-hydroxyacyl coenzyme A dehydrogenase) and ALDH9A1 (Aldehyde dehydrogenase family 9 member A1-A) could serve as potential molecular indicators of $A$. salmonicida infection at early stages [37]. Moreover, a recent genome-wide association (GWAS) study investigated the quantitative trait loci of rainbow trout related to A. salmonicida resistance [38]. However, most of these studies focus on peripheral tissues rather than the brain. Animal behaviors are mainly regulated by neurotransmitters and neuromodulators of the brain [39]. The infected trout exerted sickness behaviors including anorexia and lethargy, suggesting that furunculosis dysregulated brain functions. The limited information of brain transcriptional signatures in response to $A$. salmonicida infection will limit the better understanding of the immune mechanisms during $A$. salmonicida infection in trout (salmonids).

Although early researchers generally studied the immune and central nervous system (CNS) as separate targets due to the concept of "immune privilege", the last 30 years has witnessed the birth of brain (CNS)-immune communication and the following significant development $[40,41]$. Peripheral inflammation causes inflammatory processes in the brain and the activated immune cells (mediators), resulting from infection and inflammation, could directly interact with the brain, thus resulting in brain-regulated sickness behaviors including anorexia and reduced locomotor activity $[42,43]$, which is consistent with furunculosis symptoms in trout. Moreover, previous studies showed that the blood-brain barrier (BBB) is disrupted by bacterial infection in both mammalian and teleost species $[44,45]$, further increasing the possibility that peripheral bacterial infection challenges brain immune homeostasis. Therefore, we investigated whether A. salmonicida infection resulted in homogeneously (or heterogeneously) immune effects on CNS and peripheral immune tissues in trout.

In our study, we investigated the transcriptional profiles and functional enrichment of brains (CNS) and kidneys (peripheral tissue) of trout in response to A. salmonicida infection. We selected the brain and kidney due to the following reasons: 1 . Brain cells exert poor regenerative capacity and dysfunction in the brain (by immune cells and/or modulators) 
could lead to catastrophic effects on life. However, the immunomodulation status of trout brain in response to pathogen infection has been underestimated, so far. 2. Th kidney is a well-characterized immune tissue in teleost and serves as the major target of bacterial A. salmonicida infections [25,36]. Furthermore, salmonid has long been a model for novel gene identification because salmonid-specific whole genome duplication (ssWGD) results in duplications of the functional paralogs $[46,47]$. Therefore, we further analyzed the sequences, structure, and potential functions of immune genes and their paralogs. Our study may reveal insight into the interaction of CNS and peripheral tissues in responses to furunculosis and provide a foundation for breeding disease-resistant trout strains.

\section{Results}

\subsection{General Transcriptomic Profiles of the Brain and Kidney in Response to A. salmonicida Infection}

In trout infected with $A$. salmonicida, RNA-seq analysis showed 855 (163 down and 692 up) and 603 (306 down and 297 up) DEGs in the brain and kidney, respectively (Figure $1 \mathrm{~A}-\mathrm{C}$ ). We further observed that 5 DEGs were down-regulated in both brain and kidney, while 46 DEGs showed up-regulation in both the brain and kidney (Figure 1B,C). The statistical results of DEGs are represented in volcano plots and heatmaps (Brain: Figure 1D,F; Kidney: Figure 1E,G). The separated clusters in PCA plots indicated trout in CT and IT exerted different transcriptomic profiles in the brain and kidney (Figure 1H,I). The loading plot showed the values of each gene resulted in separated clusters in PCA plots (Figure 1J,K).
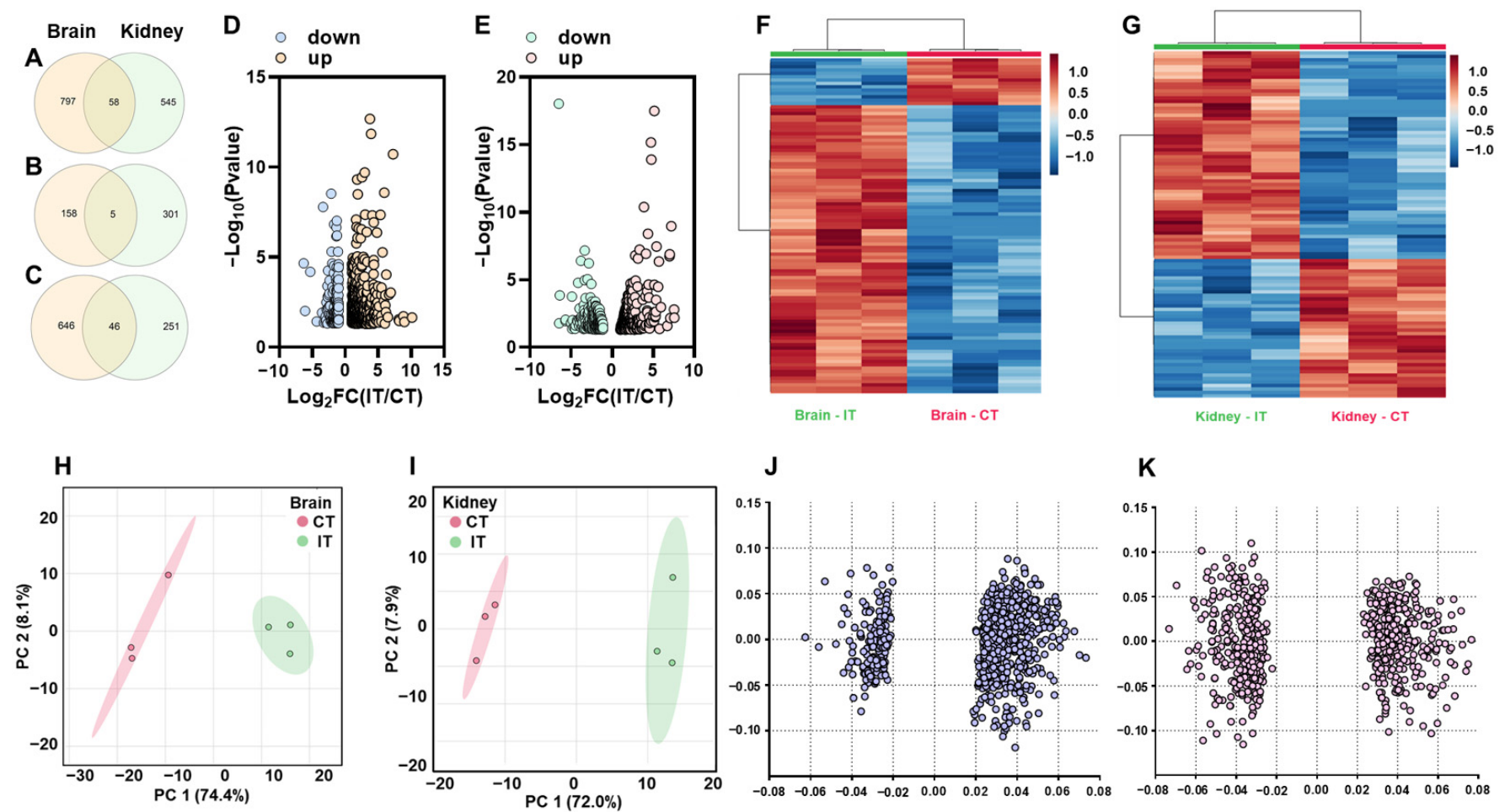

Figure 1. General transcriptomic profiles of trout in response to A. salmonicida infection. The differently expressed genes in the brain and kidney in response to A. salmonicida infection: (A) total (B) down-regulation and (C) up-regulation. The volcano plots of differently expressed genes in the brain (D) and kidney (E). The heatmaps of differently expressed genes in brain (F) and kidney (G). The heatmaps were generated from the counts (normalized by DESeq2) of differently expressed genes. The PCA plots and loading plots of differently expressed genes in the brain $(\mathbf{H}, \mathbf{J})$ and kidney $(\mathbf{I}, \mathbf{K})$. In PCA plots, the red dots show the "vector" of differently expressed genes in CT and green dots shows the "vector" of differently expressed genes in IT. In loading plot, the variables (genes) far from center $(0,0)$ showed stronger effects on separated clusters in PCA plots. 


\subsection{DEGs Commonly Identified in Brain and Kidney}

The common DEGs in both the brain and kidney are shown in heatmaps (Figure 2A). Based on further pathway enrichment analyses, we identified several key genes associated with immunomodulation, including acod1, tapasin, $h 2-q 9$, and ha2 (Figure 2B-E). The GO analyses showed that acod1 (with other genes) was involved in inflammatory regulation, cellular defenses, and cellular responses to cytokines in the brain and kidney (Figure 2F,G), and $h 2-q 9$ (with other genes) was associated with immune response and major histocompatibility complex (MHC) functions (Figure 2H). Based on the KEGG database, we observed $h 2-q 9$, $h a 2 q$, and tapasin (with other genes) were enriched in the pathways of phagosome, antigen processing and presentation, and natural killer cell mediated cytotoxicity (Figure 2I,J).
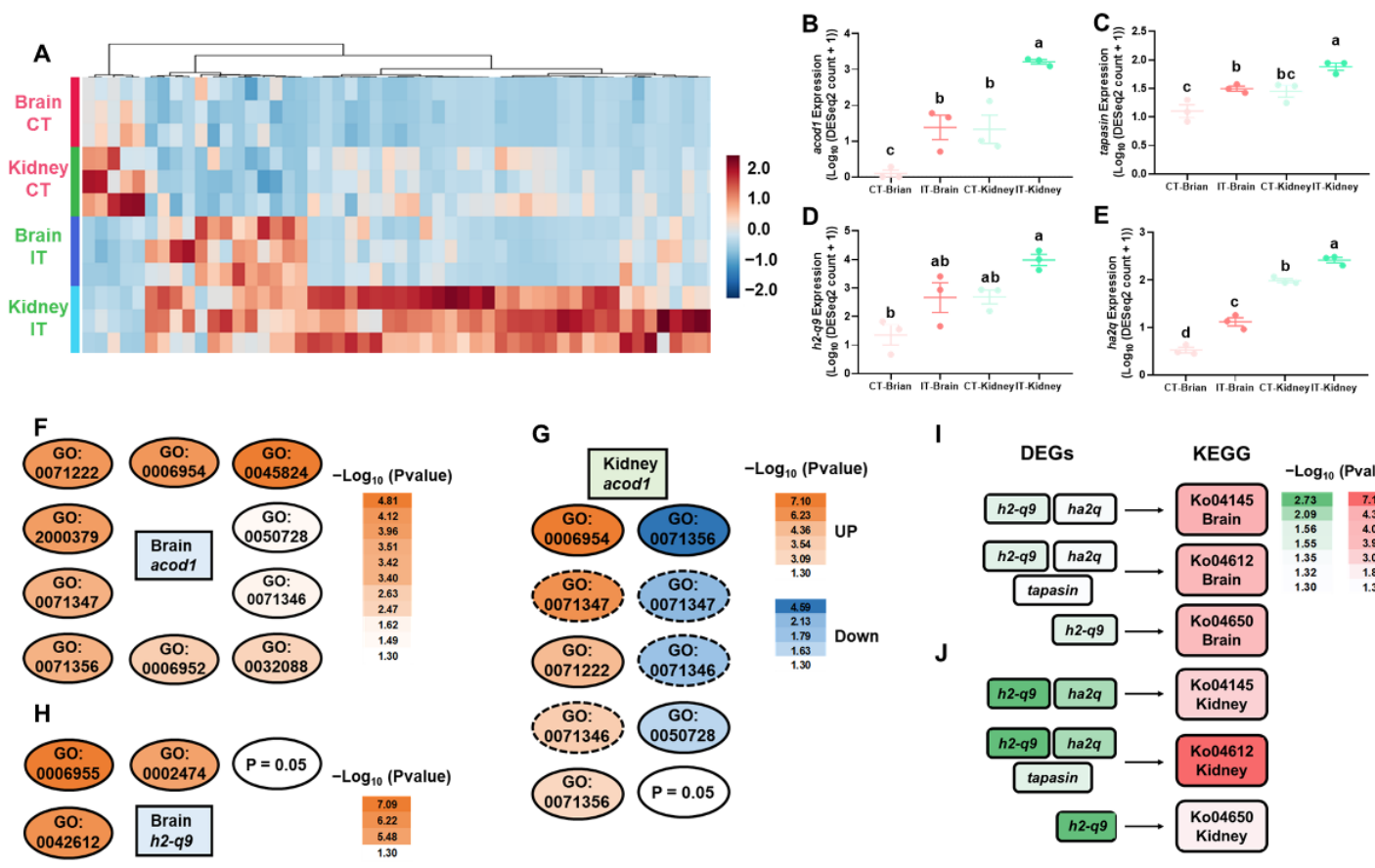

Figure 2. Differently expressed genes commonly identified in the brain and kidney in response to $A$. salmonicida infection. (A) The heatmaps of differently expressed genes commonly identified in the brain and kidney; (B-E) The interleaved scatters of acod1, tapasin, $h 2-q 9$, and $h a 2 q$ (Different letters indicate significant differences, $p<0.05$, one-way ANOVA with Tukey's test); (F,G) The GO terms associated with acod1. GO:0045824, negative regulation of innate immune response; GO:0006954, inflammatory response; GO:0071222, cellular response to lipopolysaccharide; GO:2000379, positive regulation of reactive oxygen species metabolic process; GO:0071347, cellular response to interleukin1; GO:0071356, cellular response to tumor necrosis factor; GO:0006952, defense response; GO:0032088, negative regulation of NF- $\mathrm{KB}$ transcription factor activity; GO:0071346, cellular response to interferongamma; GO:0050728, negative regulation of inflammatory response. $(\mathbf{H})$ The GO terms associated with $h 2-q 9$. GO:0006955, immune response; GO:0042612, MHC class I protein complex; GO:0002474, antigen processing and presentation of peptide antigen via MHC class I. (I,J) The KEGG pathways commonly enriched in brain and kidney with $h 2-q 9, h a 2 q$ and tapasin. Details of heatmaps, GO terms and KEGG pathways are shown in Tables S2-S4.

\subsection{Enrichment Analysis of DEGs in Brain and Kidney}

Based on GO enrichment analyses of DEGs, we showed that, in the infected trout, up-regulated DEGs were significantly enriched in GO terms associated with immune functions (Figure 3A), while the down-regulated DEGs were significantly enriched with GO terms of neural functions and cell cycle (Figure 3B). Predicted functional networks between the up-regulated and down-regulated DEGs are shown (Figure 3C,D). The KEGG pathway enrichment analyses indicated that infected trout showed up-regulated KEGG 
pathways associated with immune and neuro/endocrine functions (Figure 3E, Table S4), while the down-regulated KEGG pathways were involved in cell cycle and steroid hormone functions (Figure 3F, Table S4). The DEGs associated with enriched GO terms and KEGG pathways are shown by heatmap (Figure 3G-J). Based on GO and KEGG analyses, the putative pathways, which were involved in immune defenses, neural functions, and cell cycle of trout brain in response to $A$. salmonicida infection were proposed (Figure $3 \mathrm{~K}$, more details in Discussion).

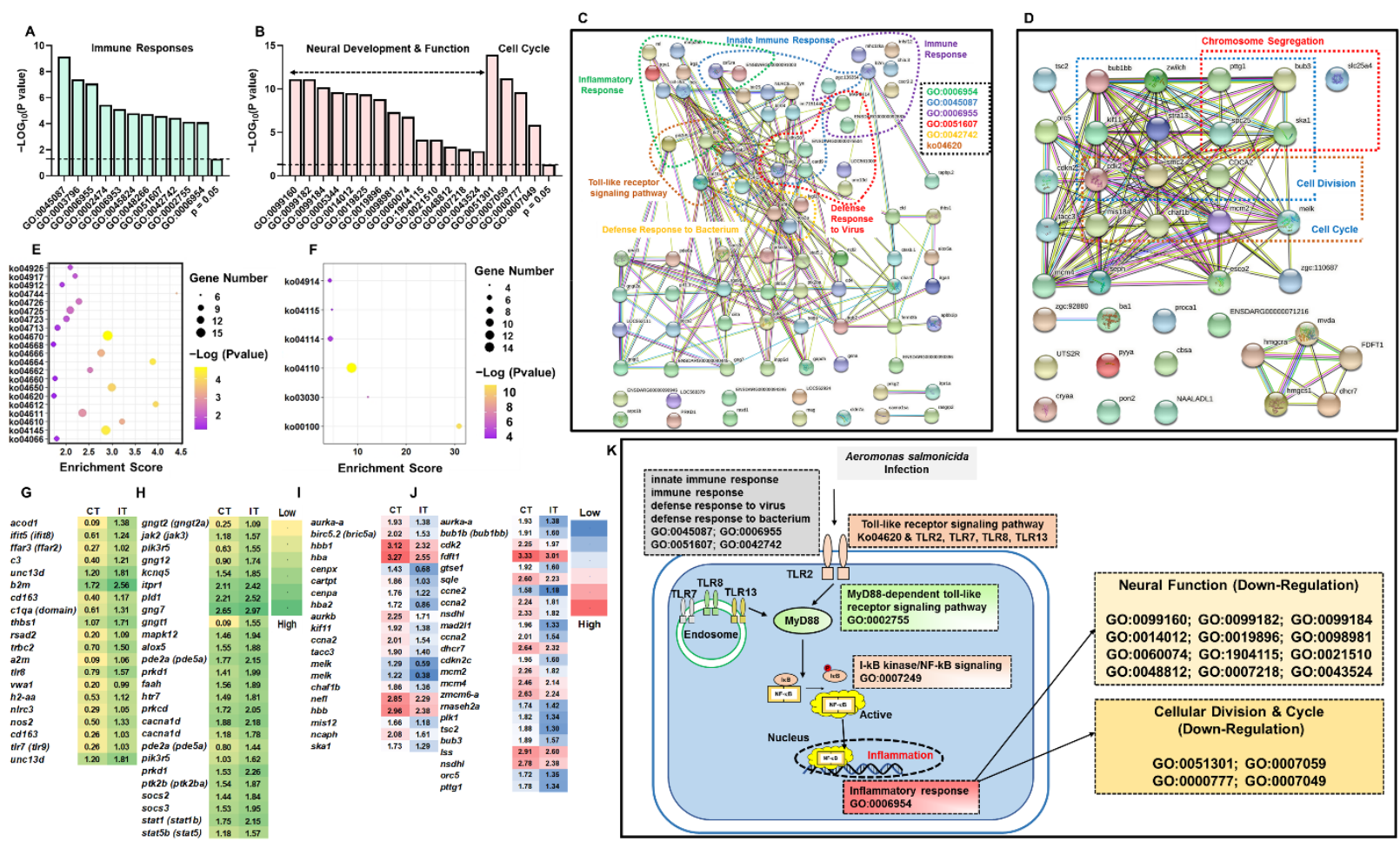

Figure 3. The enrichment analyses of DEGs in the brain in response to A. salmonicida infection. (A) GO terms associated with immune functions (up-regulated in infected trout); (B) GO terms associated with neural functions and cell cycle (down-regulated in infected trout); Predicted functional networks between the up-regulated genes (C) and down-regulated genes (D). The networks were established by the database of STRING Version 11 (http:/ / string-db.org/, last accessed on 21 December 2021, based on zebrafish). (E) KEGG pathways associated with immune and neuro/endocrine functions (up-regulated in infected trout); (F) KEGG pathways associated with cell cycle and steroid hormone functions (down-regulated in infected trout). (G-J) Heatmap of the candidate genes. (G) Up-regulated genes enriched in GO terms; (H) Up-regulated genes enriched in KEGG pathways; (I) Down-regulated genes enriched in GO terms; (J) Down-regulated genes enriched in KEGG pathways. (K) The putative pathways of trout brain in response to A. salmonicida infection. Details of heatmaps, GO terms, and KEGG pathways are shown in Tables S4-S6.

The RNA-seq data showed that $A$. salmonicida infections resulted in great influences on immune stimulation, neural functions, and endocrine systems in the kidney, which is consistent with the results in brain. Based on GO enrichment analyses, the infected trout showed up-regulated GO terms involved in immune functions (Figure 4A, Table S4) and down-regulated GO terms associated with neural functions (Figure 4B, Table S4). The KEGG pathway analyses showed the immune-related pathways and endocrine functions were upregulated (Figure 4C,D, Table S4). Functional networks between DEGs were predicted by the database of STRING Version 11 (Figure 4E). 

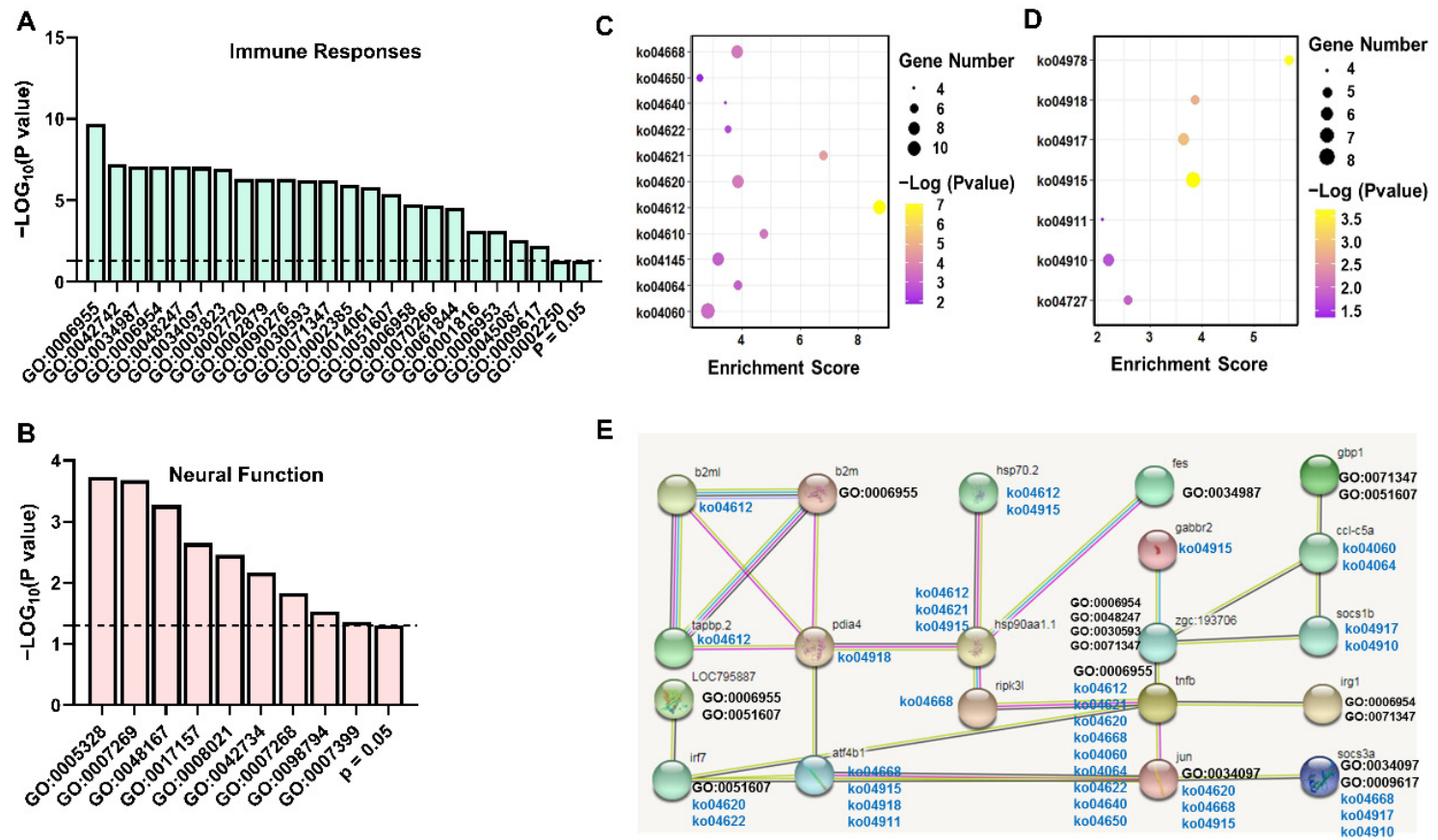

Figure 4. The enrichment analyses of DEGs in the kidney in response to A. salmonicida infection. (A) GO terms associated with immune functions (up-regulated in infected trout); (B) GO terms associated with neural functions (down-regulated in infected trout). (C) KEGG pathways associated with immune functions (up-regulated in infected trout); (D) KEGG pathways associated endocrine functions (up-regulated in infected trout). (E) Predicted functional networks between the DEGs. The networks were established by the database of STRING Version 11 (http:/ / string-db.org/, last accessed on 21 December 2021, based on zebrafish). Details of GO terms and KEGG pathways are shown in Table S4.

\subsection{Identification of the Novel Macrophage csf-1r}

Colony stimulating factor 1 receptor (CSF-1R) serves as the receptor of CSF-1 and interleukin-34 (IL-34). The CSF-1R signaling plays an important role in regulating cellular proliferation, differentiation, and survival [48-52]. Based on brain GO enrichment analyses, we identified three csf- $1 r$ paralogs were significantly changed after $A$. salmonicida infection and enriched in $\mathrm{GO}$ terms associated with innate immune and inflammatory responses (GO:0045087 and GO:0006954, Figure 3A). We further searched the genomic data of rainbow trout (GCA_013265735.3), identifying four csf-1r paralogs with conserved transmembrane and juxtamembrane domains (Figure 5A,B). Based on the crystal structure of human macrophage CSF-1R (3KRJ), we built a model between trout and human CSF-1Rs via the SWISS-MODEL server (https: / / swissmodel.expasy.org/, last accessed on 21 December 2021). Trout and human CSF-1R showed relatively conserved amino acid sequences in juxtamembrane domains (Figure 5C-F), including JM-B (buried region), JM-S (switch motif) and JM-Z (zipper region). We also identified the most conserved Tyrosine ( $\mathrm{Y}$ ) in JM-B, JM-S, and JM-Z (Figure 5C-F).

Based on RNA-Seq data, we observed that brain il-34b, csf-1ra2, and csf-1rb2 showed up-regulation in infected trout while the kidney csf-1rb1 showed up-regulation in infected trout (Figure $5 \mathrm{G}, \mathrm{H})$. In the brain, the $c s f-1 b 2$ exhibited a significantly positive correlation with the $c s f-1 r b 1$, and $i l-34 b$ exerted positive correlation with receptors of $c s f-1 r a 2$, csf$1 r b 1$, and $c s f-1 r b 2$ (Figure 5I,J). In the kidney, the $c s f-1 b 2$ showed a significantly positive correlation with $c s f-1 r b 1$, and il-34b showed a significantly positive correlation with csf-1ra1 (Figure 5K,L). 


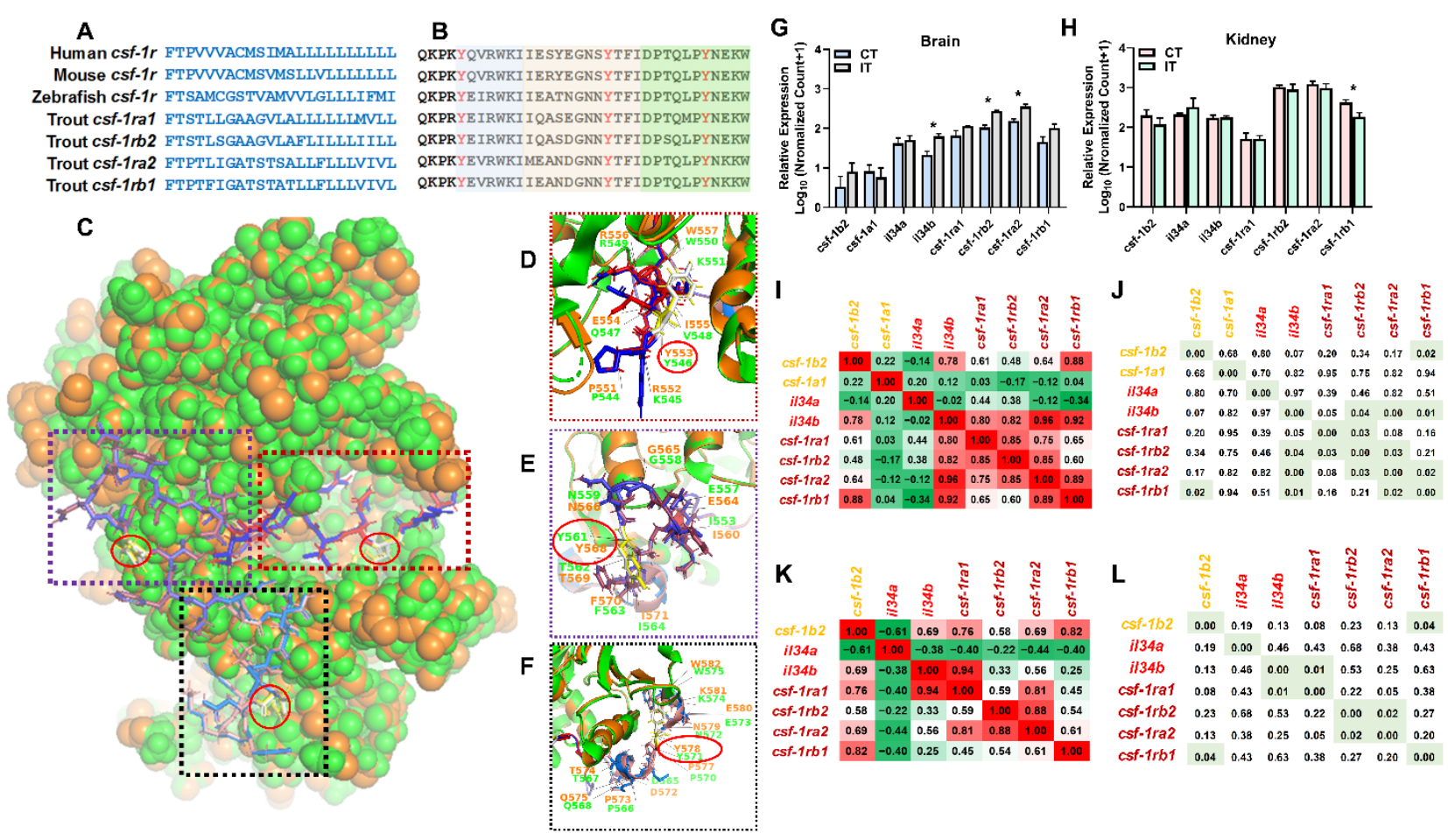

Figure 5. Identification of novel csf-1r gene subtypes and characterization of the expression and function. (A,B) Alignment of novel trout csf-1r gene subtypes to teleost and mammalian species. (A) Alignment of transmembrane domains of novel trout CSF-1R subtypes to teleost and mammalian species. (B) Alignment of juxtamembrane domains of novel trout $c s f-1 r$ gene subtypes to teleost and mammalian species. The JM-B (buried region), JM-S (switch motif), and JM-Z (zipper region) are shaded by different colors and the conserved tyrosine residues are highlighted red. The whole sequence alignment and phylogenetic tree of CSF-1R are shown in Figures S2 and S3. (C-F) Comparison of the predicted crystal structure of JM-B (D), JM-S (E), and JM-Z (F) between trout and human CSF$1 \mathrm{R}$ orthologous. The green illustration shows the human CSF-1R, and the orange illustration shows the trout CSF-1RA1 (LOC100136949). The conserved tyrosine residues are highlighted by a red circle. The comparison model was built via the SWISS-MODEL server (https: / /swissmodel.expasy.org/, last accessed on 21 December 2021) with human macrophage CSF-1R (3KRJ). (G-L) The expression profiles of $c s f-1$ and csf- $1 r$ systems in brain $(\mathbf{G})$ and kidney $(\mathbf{H})$. The Pearson's correlation analysis ((I), brain; (K), kidney) and $p$ value $((\mathbf{J})$, brain; $(\mathbf{L})$, kidney) of $c s f-1$ and $c s f-1 r$ systems in trout in CT and IT. The "** indicates a significant difference between CT and IT $(p<0.05)$.

\section{Discussion}

\subsection{Key Immune-Related Genes Commonly Identified in the Brain and Kidney}

We identified DEGs of acod1, h2-q9, ha2q, and tapasin were consistently up-regulated in the brain and kidney. The gene ontology and pathway analyses further revealed these genes play important roles in immunomodulation (Figure 2). The Acod1 (Aconitate decarboxylase 1, also known as immune-responsive gene 1, IRG1) gene was first identified in mouse macrophage cell line in response to lipopolysaccharide (LPS) stimulation [53]. The recent medical studies indicated that ACOD1 is markedly up-regulated by pathogen infection and serves as a key regulator of inflammation and infection [54-56]. In this study, we observed that infected trout showed an $~ 15$ and 2.4-fold increase of acod1 expressions in the brain and kidney, respectively (Figure 2), which is consistent with previous studies showing that European common carp (Cyprinus carpio carpio L.) exerts up-regulated acod1 expression in responses to LPS [57]. Our enrichment analyses showed up-regulated acod1 was highly enriched in GO terms, such as immune response (GO:0006955), inflammatory response (GO:0006954), and cellular response to LPS (GO:0071222) (Figure 2), which suggested a conserved immunometabolism reprogram between mammals and teleost. Moreover, we 
showed that the kidney exhibited higher basal acod1 expression ( 160-fold higher than brain), while the brain showed higher $A$. salmonicida-induced acod1 expression ( 118 versus 34-fold increase), probably suggesting that CNS and peripheral tissues exerted distinct metabolic signatures during basal and activated immune states.

MHC are polymorphic membrane glycoproteins that play an important role in regulating immune functions in response to self and invading antigens [58,59]. The MHC class I molecules present intracellular peptide fragments of the host cells, while MHC class II molecules present the exogenous antigens [60-62]. In infected trout, the up-regulated $h 2-q 9$ (LOC110496224) and ha2q (LOC110537685) were associated with biological functions of class I and class II histocompatibility and the up-regulated tapasin serves as a chaperone for MHC class I assembly [63]. Moreover, these up-regulated DEGs were enriched in KEGG pathways of antigen processing and presentation (ko04612) and/or phagosome (ko04145, Figure 2). Consistent with our results, previous studies showed that Salmonids exhibits crosstalk between MHC class I and II pathways in response to A. salmonicida or virus infection $[64,65]$. Therefore, we might propose that MHC class I could also be activated by cross presentation during pathogen invasion in teleost, which agrees with studies in medical science showing MHC class I pathway can be activated by exogenous antigens via cross presentation [66]. Our data might provide insights for future studies on identification of molecular markers for A. salmonicida-resistant trout families due to the fact that MHC polymorphism is associated with resistance/susceptibility to A. salmonicida in Salmonids $[65,67]$.

\subsection{The Pathway Analysis of Neural and Peripheral Immune Modulation}

Inflammation represents a cascade of immune responses that aims to protect the body and defend invaders [68]. Although the brain has long been considered as an immune-privileged organ, accumulating studies in recent decades reveal that activation of immune cells in the brain (such as microglial cells and astrocytes) results in neuroinflammation $[69,70]$. Compared to human and mice studies, studies on fish neuroinflammation (or neuroimmunology) are limited. Our studies showed that the DEGs were significantly enriched in functional pathways associated with pathogen defenses, immune responses, inflammatory regulations, and dysregulated neural functions (Figure 3). Biomedical studies confirmed that neuroinflammation, which could originate from infectious pathogens, contributes to the pathogenesis of neurodegeneration diseases [71-74]. Studies of psychoneuroimmunology further revealed that alterations in the brain immune state are associated with sickness (or depression) behaviors, including psychomotor slowing, anorexia, and fatigue [75]. For example, meta-analyses of psychoneuroimmunology showed tumor necrosis factor (TNF)- $\alpha$, interleukin (IL)-1, and IL-6 levels were significantly increased in patients with depression symptoms [75-77]. The depression subjects exert overlapped features with symptoms of sickness behavior [75]. Consistently, trout in the IT group showed significantly increased brain il-6 and il-6r $\alpha$ (il-6 receptor subunit $\alpha$ ) expressions and up-regulated enrichments of cellular response to lipopolysaccharide (GO:0071222), cellular response to interleukin-1 (GO:0071347), TNF signaling pathway (ko04668) and Cytokine-cytokine receptor interaction (ko04060, Table S4). Based on these evidences, we proposed that pathogen infection could disturb the homeostasis of immunomodulation and neuromodulation, thus resulting in typical disease characteristics of infected trout (e.g., symptoms of anorexia and lethargy).

Toll-like receptors (TLRs) play important roles in regulating innate immune and the inflammatory responses [78,79]. Multiple members are identified in the TLRs family in mammals, including cell surface receptors (TLR1, TLR2, TLR4, TLR5, TLR6, and TLR10) and intracellularly receptors (TLR3, TLR7, TLR8, TLR9, TLR11, TLR12, and TLR13). TLRs, which serve as pattern recognition receptors, recognize the foreign microbes/molecules, and subsequently trigger the proinflammatory regulation by activating MyD88, NF- $\mathrm{kB}$, and other signaling cascades [80]. Our study showed the transcriptional levels of $t l r 2, t l r 7, t l r 8$, and $t \operatorname{lr} 13$ were up-regulated in the brain of infected trout (Figure 4 and Figure S1). Moreover, 
the expression profiles of genes associated with MyD88 and NF- $\mathrm{B}$ signaling pathways were significantly enriched and increased (Figure 3). Our results were consistent with previous studies, showing that TLRs systems in peripheral immune tissues are involved in immunomodulation in Salmonids in response to A. salmonicida infection [81,82]. Taken together, these results suggested that the immune responses could trigger inflammation in both brain and peripheral tissues, rather than immune privilege.

Based on previous studies in the biomedical field [74,75,78-80] and our RNA-Seq data, we might propose a potential pathway showing that bacterial infection resulted in neuroinflammation (or neuroimmunology) in trout infected by A. salmonicida. After infection, trout exert defenses to foreign pathogens and initiate immune responses. TLR2 could detect the extracellular pathogen molecules while the intracellularly pathogen molecules were recognized by TLR7, TLR8, and TLR13. The activated TLRs trigger the downstream MyD88 and NF- $\mathrm{KB}$ signaling, enhancing transcriptional levels of genes involved in inflammatory regulation. Neuroinflammation further results in down-regulation of neural development and function (Figure 3).

Consistently with enrichment results of the brain, the up-regulated genes were enriched in immune functions of antigen presentation (ko04145, ko04612), toll-like receptors and TNF signaling (ko04620, ko04668), and complement and coagulation cascades (ko04610, Figure 4, Table S4). The kidney also exhibited significantly up-regulated DEGs associated with endocrine functions (Figure 4, Table S4). The products (cytokines, hormones, and neurotransmitters) and cognate receptors of immune-neuro-endocrine axis coexist in cells, thus playing an important role in regulating and recovering homeostasis in response to pathogen and stress in both mammals and teleost [83-87]. The kidney showed up-regulated signaling pathways associated with estrogen, prolactin, and insulin signaling (ko04915, ko04917, ko04910), insulin secretion (ko04911), and thyroid hormone synthesis (ko04918, Figure 4, Table S4), which agreed with previous studies showing endocrine products, such as prolactin and estrogen, and exerts immune-regulatory effects on fish (reviewed in $[84,88,89])$.

\subsection{Identification of Novel Genes Associated with Immunomodulation}

CSF-1 is an important regulator in regulating macrophage differentiation and survival, which plays a vital role in immunomodulation [90,91]. The $c s f-1$ gene is extensively expressed in multiple species including mammals, birds, and teleost [92-94]. Only one csf-1 gene is identified in most mammals, while teleost (excepting Salmonids) exerts two csf-1 (csf- $1 a$ and $c s f-1 b$ ) copies due to the additional whole genome duplication (three rounds of genome duplication, also termed as teleost-specific WGD) $[95,96]$. In this study, we identified four csf-1 paralogs in trout, which is consistent with the fact that Salmonids' ancestry exerts four rounds of genome duplication [97]. The CSF-1R, a glycoprotein encoded by the c-fms proto-oncogene [51], serves as the receptor of CSF. Consistently, we identified four csf-1r paralogs in rainbow trout. Phylogenetic analysis indicated orthologous relationships of $c s f-1$ and $c s f-1 r$ between mammalian and teleost equivalents (Figure S3), potentially suggesting the conserved functions in immunomodulation.

In this study, A. salmonicida infection resulted in significantly increased csf-1ra2 and $c s f-1 r b 2$ expressions in the brain and decreased $c s f-1 r b 1$ expression in the kidney, suggesting the functional diversity of $c s f-1 r$ paralogs and the potential tissue-specific expressions. Further enrichment analyses showed up-regulated brain csf-1r genes were involved in up-regulated GO terms associated with innate immune response (GO:0045087) and inflammatory response (GO:0006954, Figure 3 and Table S4). Our results agree well with previous studies showing that the CSF-1 system is involved in immunoregulatory property in teleost $[98,99]$. Biomedical studies confirmed that both CSF-1 and interleukin-34 (IL-34) activate human CSF-1R. In this study, we observed brain $i l-34 b$ was up-regulated after the A. salmonicida infection, which is consistent with the expression pattern of csf-1ra2 and $c s f-1 r b 2$. Moreover, the il-34 expression was positively correlated with csf-1r expressions 
(Figure 5). Further studies might focus on pharmacological characteristics of $i l-34$ and csf- $1 r$ via in vitro studies.

\section{Materials and Methods}

\subsection{Ethics Statement}

All experiments were conducted in accordance with guidelines of Animal Research and Ethics Committee of Ocean University of China (Permit Number: 2014201), the National Institutes of Health Guidelines for the Care and Use of Laboratory Animals (NIH Publications NO. 8023, revised 1987). Our research did not involve endangered or protected species. In this study, trout juveniles were immature, and the effect of gender was not considered.

\subsection{Experiment Design and Sample Collection}

Rainbow trout ( $\sim 10 \mathrm{~g}$ and $\sim 8 \mathrm{~cm}$ ) were obtained from trout farm in Linqu, Shandong Province, and then acclimated for 7 days in individual aquariums at $\sim 17^{\circ} \mathrm{C}$ with the photoperiod of 12:12 (hours) of light and dark. During bacterial challenge, trout were randomly classified into two groups as control trout group (CT) and infected trout group (IT), respectively. IT contained two replications and each replication had 20 individuals $(n=20)$. Based on our previous study [100], trout of IT were intraperitoneally injected with $0.2 \mathrm{~mL}$ of $A$. salmonicida $\left(1 \times 10^{8} \mathrm{CFU} / \mathrm{mL}\right)$, while trout in CT were injected by an equal volume $(0.2 \mathrm{~mL})$ of phosphate buffer solution (PBS). Furunculosis symptoms (Figure S4) were observed at $48 \mathrm{~h}$ after infection; therefore, trout in both the CT and IT groups were euthanized by MS-222 (35-45 mg/L) and then sampled at $48 \mathrm{~h}$. The brains and kidneys were collected after washing with PBS (remove blood and fat cells) and then stored at $-80^{\circ} \mathrm{C}$ for further analyses. Two individuals in IT were pooled as one sample to reduce the individual variations for further analyses.

\subsection{RNA-Seq Analysis}

Total RNA of the brain and kidney was extracted using TRIzol reagent (Invitrogen, Carlsbad, CA, USA), and the RNA quality was evaluated by NanoDrop ND-1000 (Thermo Fisher Scientific, Wilmington, DE, USA) and 1\% agarose gel electrophoresis. One transcriptome library was constructed by pooling equal quantities of RNA from two individuals. A total of 12 libraries ( 2 tissues $\times 3$ replicated samples $\times 2$ treatment groups) were constructed via TruSeq ${ }^{\mathrm{TM}}$ RNA Sample Prep Kit (Illumina, San Diego, CA, USA). The Illumina Hiseq X Ten platform (OE biotech Co., Ltd., Shanghai, China) was used to generate $150 \mathrm{bp}$ pairedend raw reads. Raw data were processed using the Trimmomatic [101]. The clean reads were obtained by removing reads with low quality or reads containing poly-N. The clean reads were then mapped to the reference genome of rainbow trout (GCA_013265735.3) using histat2 [102]. The sequence reads are available at the NCBI sequence read archive (SRA), accession number PRJNA753277.

The Fragments Per kb Per Million Reads (FPKM) value of each gene was calculated using cufflinks, and the read counts of each gene were obtained by htseq-count. Differentially expressed genes (DEGs) were identified by the DESeq2 R package $[103,104]$ and the DEGs were identified as $p$-value $<0.05$ and $\mid \log _{2}$ (fold change) $\mid>1$. Gene Ontology (GO) and Kyoto Encyclopedia of Genes and Genomes (KEGG) pathway enrichment analyses of DEGs were evaluated, primarily focusing on functional/signaling pathways associated with immunomodulation and neural functions.

\subsection{Identification of Novel Immune Genes Based on RNA-Seq Data}

The RNA-Seq data showed that macrophage colony stimulating factor 1 (csf-1, also known as $c f m s)$ paralogs and their cognate receptors (csf-1r) were significantly involved in immune responses of trout in response to $A$. salmonicida challenges. To identify the novel paralogs of $c s f-1$ and $c s f-1 r$, the whole genomic sequence database (GCA_013265735.3) of rainbow trout was researched using the TBLASTN program. The CSF-1 and CSF-1R 
full-length amino acid sequences of human and zebrafish were used as the queries with an E-value of $1 \times 10^{-5}$. The TBLASTN and Clustal $W$ were used to remove redundant sequence(s), thus generating initial candidate sequences for further analysis.

Phylogenetic analysis was conducted to validate the annotation of the potential CSF-1 and CSF-1R paralogs in trout. The amino acid sequences of human (Homo sapiens), mice (Mus musculus), zebrafish (Danio rerio), medaka (Oryzias latipes), channel catfish (Ictalurus punctatus), Atlantic salmon (Salmo salar) and other teleost were used for the construction of the phylogenetic tree. An alignment of multiple amino acid sequences was performed using ClustalW. The neighbor-joining (NJ) method and Jones-Taylor-Thornton (JTT) model were used for conducting phylogenetic and molecular evolution analysis by using MEGA 7.0 software. Bootstrap tests with 1000 replications were used to test the phylogenetic tree and gaps were removed via pairwise deletion. Comparison between trout and mammalian CSF-1R (human, 3KRJ) were generated with the SWISS-MODEL (https://swissmodel. expasy.org/, last accessed on 21 December 2021) and PyMOL software package.

\subsection{Validation of RNA-seq Data by $q P C R$}

Thirteen DEGs were selected for qPCR analysis. They were shown in Figure 6 and Table S1. The specific amplification of each primer pairs was validated, and the amplification efficiency was calculated as $\mathrm{E}(\%)=\left(10^{(-1 / \text { slopes })}-1\right) \times 100$. The $\beta$-actin was used as an internal reference gene [100]. The qPCR was performed on StepOnePlus ${ }^{\mathrm{TM}}$ Real-time PCR system (Applied Biosystems, Carlsbad, CA, USA). The reaction volume was $10 \mu \mathrm{L}$, containing $1 \mu \mathrm{L}$ cDNA, $5 \mu \mathrm{L}$ SYBR $^{\circledR}$ FAST qPCR Master Mix, $0.2 \mu \mathrm{L}$ forward (reverse) primer, and 3.6 $\mu \mathrm{L}$ RNAase-free water. The qPCR was performed by following the following program: $95^{\circ} \mathrm{C}$ for $30 \mathrm{~s}, 40$ cycles of $95^{\circ} \mathrm{C}$ for $10 \mathrm{~s}$ and $\mathrm{Tm}$ for $30 \mathrm{~s}$, followed by $72{ }^{\circ} \mathrm{C}$ for $30 \mathrm{~s}$. The relative expression levels of mRNA were calculated using the comparative $2^{-\Delta \Delta C T}$ method [105].

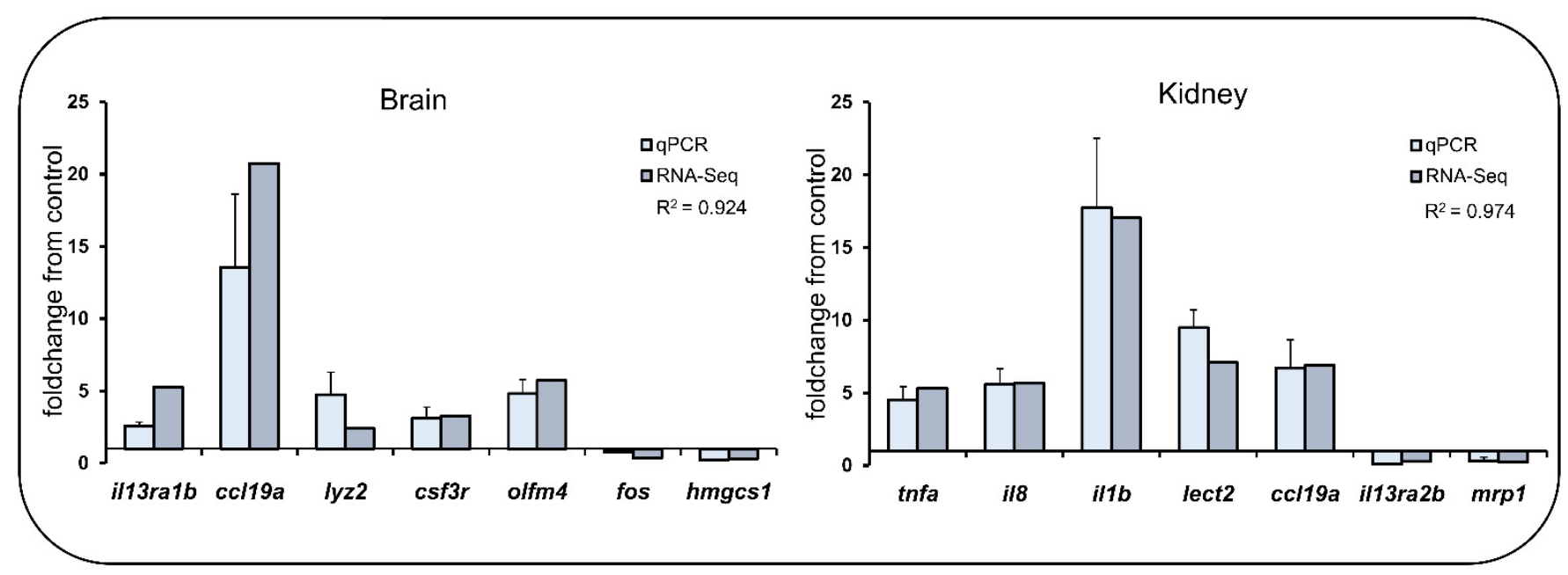

Figure 6. RNA-Seq validation. Comparison of gene expression levels between RNA-seq and qPCR. The relative expression values were normalized to $\beta$-actin gene expression for qPCR analysis. Foldchange refers to the fold-change between the CT and IT.

\subsection{Statistical Analysis}

Based on published medical and fishery studies [106,107] the RNA-Seq data (count normalized by DESeq2 [104]) were uploaded to the websites of MetaboAnalyst and NetworkAnalyst (https://www.xialab.ca/tools.xhtml, last accessed on 21 December 2021) for data processing and analyses [108]. The data were analyzed by principal components analysis (PCA), loading plots and heatmaps via a multivariate analysis module of MetaboAnalyst. The univariate analyses of gene expression were analyzed by GraphPad Prism 8.0. One-way analysis of variance (ANOVA) was used to evaluate the effect of $A$. salonmicida 
challenge on gene expressions of trout in CT and IT. Means of gene expressions were further compared by Tukey's multiple range tests when significant differences were observed by one-way ANOVA. The differences were considered statistically significant when the $p<0.05$. Results were expressed as mean \pm standard error (means \pm S.E.). The correlation analysis of gene expression was investigated by MetaboAnalyst and GraphPad Prism 8.0 via Pearson's correlation analysis.

\section{Conclusions}

The pairwise comparison between trout of the CT and IT groups (Figure 7) showed that the kidney and brain shared 50 up-regulated DEGs with signaling pathways including antigen presentation (ko04145, ko04612), toll-like receptors and cytokine functions (ko04620, ko04668), and complement and coagulation cascades (ko04610). This evidence confirmed that $A$. salmonicida infections resulted in homogeneously immune effects on both central and peripheral tissues, rather than CNS immune privilege. In the brain, the up-regulated DEGs were associated with activation of the toll-like receptor signaling pathways, thus triggering neuroinflammation and dysregulated neuro functions. Therefore, the typical disease characteristics of infected trout, such as symptoms of anorexia and lethargy, could be partly attributed to the dyshomeostasis between immunomodulation and neuromodulation in brain. In addition, kidneys also showed up-regulated endocrine networks involved in estrogen, prolactin, and insulin signaling pathways and thyroid hormone synthesis, supporting the bi-directional crosstalk between endocrine and immune systems in response to pathogen infection.

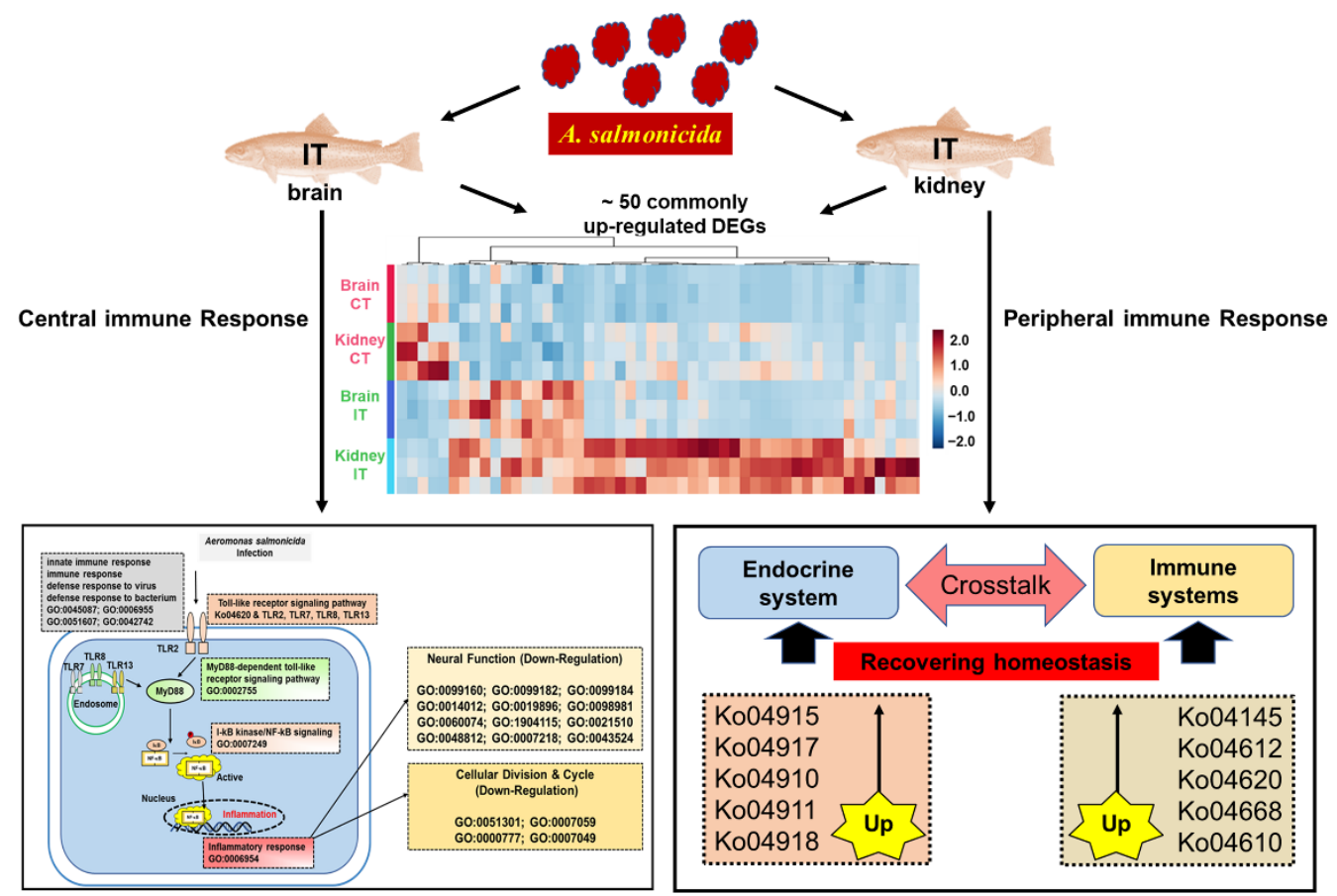

Figure 7. Putative pathways involved in central and peripheral responses based on RNA-Seq signatures.

Supplementary Materials: The following are available online at https:/ /www.mdpi.com/article/10 $.3390 /$ ijms23031340/s1.

Author Contributions: Conceptualization: J.L., Z.H. and H.W.; methodology: M.L.; software: M.L. and Z.H.; validation, M.L., Z.H. and H.W.; formal analysis: M.L. and Z.H.; investigation: M.L. and Z.H.; resources: J.L. and H.W.; data curation: Z.H. and H.W.; writing-original draft preparation: M.L., Z.H. and H.W.; writing-review and editing: Z.H. and H.W.; visualization: M.L. and Z.H.; supervision: Z.H. and H.W.; project administration: M.L., X.Y., C.Z. and H.Z.; funding acquisition: H.W. All authors have read and agreed to the published version of the manuscript. 
Funding: This research was funded by Blue Granary Science and Technology Innovation (Grant ID 2019YFD0901000) and Major technology innovation and application projects in Shandong provincebreeding of excellent trout species for open-sea farming (Grant ID SD2019YY006).

Institutional Review Board Statement: Not applicable.

Informed Consent Statement: Not applicable.

Data Availability Statement: Data are contained within the article.

Conflicts of Interest: The authors declare no conflict of interest.

\section{References}

1. Tidwell, J.H.; Allan, G.L. Fish as food: Aquaculture's contribution. EMBO Rep. 2001, 2, 958-963. [CrossRef] [PubMed]

2. Naylor, R.L.; Goldburg, R.J.; Primavera, J.H.; Kautsky, N.; Beveridge, M.C.; Clay, J.; Folke, C.; Lubchenco, J.; Mooney, H.; Troell, M. Effect of aquaculture on world fish supplies. Nature 2000, 405, 1017-1024. [CrossRef] [PubMed]

3. Naylor, R.L.; Hardy, R.W.; Buschmann, A.H.; Bush, S.R.; Cao, L.; Klinger, D.H.; Little, D.C.; Lubchenco, J.; Shumway, S.E.; Troell, M. A 20-year retrospective review of global aquaculture. Nature 2021, 591, 551-563. [CrossRef] [PubMed]

4. Belton, B.; Thilsted, S.H. Fisheries in transition: Food and nutrition security implications for the global South. Glob. Food Sec. 2014, 3, 59-66. [CrossRef]

5. Béné, C.; Arthur, R.; Norbury, H.; Allison, E.H.; Beveridge, M.; Bush, S.; Campling, L.; Leschen, W.; Little, D.; Squires, D.; et al Contribution of Fisheries and Aquaculture to Food Security and Poverty Reduction: Assessing the Current Evidence. World Dev. 2016, 79, 177-196. [CrossRef]

6. Thilsted, S.H.; Thorne-Lyman, A.; Webb, P.; Bogard, J.R.; Subasinghe, R.; Phillips, M.J.; Allison, E.H. Sustaining healthy diets: The role of capture fisheries and aquaculture for improving nutrition in the post-2015 era. Food Policy 2016, 61, 126-131. [CrossRef]

7. Belton, B.; Little, D.C.; Zhang, W.; Edwards, P.; Skladany, M.; Thilsted, S.H. Farming fish in the sea will not nourish the world Nat. Commun. 2020, 11, 5804. [CrossRef]

8. Khansari, A.R.; Balasch, J.C.; Vallejos-Vidal, E.; Parra, D.; Reyes-López, F.E.; Tort, L. Comparative immune- and stress-related transcript response induced by air exposure and Vibrio anguillarum bacterin in rainbow trout (Oncorhynchus mykiss) and gilthead seabream (Sparus aurata) mucosal surfaces. Front. Immunol. 2018, 9, 856. [CrossRef]

9. Yu, Y.; Wang, Q.; Huang, Z.; Ding, L.; Xu, Z. Immunoglobulins, Mucosal Immunity and Vaccination in Teleost Fish. Front. Immunol. 2020, 11, 2597. [CrossRef]

10. Ndong, D.; Chen, Y.Y.; Lin, Y.H.; Vaseeharan, B.; Chen, J.C. The immune response of tilapia Oreochromis mossambicus and its susceptibility to Streptococcus iniae under stress in low and high temperatures. Fish Shellfish Immunol. 2007, 22, 686-694. [CrossRef]

11. Yada, T.; Tort, L. 10-Stress and Disease Resistance: Immune System and Immunoendocrine Interactions. In Biology of Stress in Fish; Schreck, C.B., Tort, L., Farrell, A.P., Brauner, C.J., Eds.; Fish Physiology: Amsterdam, The Netherlands, 2016; Volume 35, pp. 365-403.

12. Janda, J.M.; Abbott, S.L. The genus Aeromonas: Taxonomy, pathogenicity, and infection. Clin. Microbiol. Rev. 2010, $23,35-73$. [CrossRef] [PubMed]

13. Dalsgaard, I.; Gudmundsdóttir, B.K.; Helgason, S.; Høie, S.; Thoresen, O.F.; Wichardt, U.P.; Wiklund, T. Identification of atypical Aeromonas salmonicida: Inter-laboratory evaluation and harmonization of methods. J. Appl. Microbiol. 1998, 84, 999-1006. [CrossRef] [PubMed]

14. Park, S.Y.; Han, J.E.; Kwon, H.; Park, S.C.; Kim, J.H. Recent insights into Aeromonas salmonicida and its bacteriophages in aquaculture: A comprehensive review. J. Microbiol. Biotechnol. 2020, 30, 1443-1457. [CrossRef] [PubMed]

15. Austin, B.; Austin, D. Bacterial Fish Pathogens: Diseases of Farmed and Wild Fish; Springer: Dordrecht, The Netherlands, 2007; ISBN 978-1-4020-6068-7. [CrossRef]

16. Farto, R.; Milton, D.L.; Bermúdez, M.B.; Nieto, T.P. Colonization of turbot tissues by virulent and avirulent Aeromonas salmonicida subsp. salmonicida strains during infection. Dis. Aquat. Organ. 2011, 95, 167-173. [CrossRef] [PubMed]

17. Li, X.; Ringø, E.; Hoseinifar, S.H.; Lauzon, H.L.; Birkbeck, H.; Yang, D. The adherence and colonization of microorganisms in fish gastrointestinal tract. Rev. Aquac. 2019, 11, 603-618. [CrossRef]

18. Shaalan, M.; El-Mahdy, M.; Theiner, S.; Dinhopl, N.; El-Matbouli, M.; Saleh, M. Silver Nanoparticles: Their Role as Antibacterial Agent against Aeromonas salmonicida Subsp. salmonicida in Rainbow Trout (Oncorhynchus mykiss). Res. Vet. Sci. 2018, 119, 196-204. [CrossRef] [PubMed]

19. Bernoth, E.-M. Furunculosis: The history of the disease and of disease research. In Furunculosis; Academic Press: Cambridge, MA, USA, 1997; pp. 1-20. [CrossRef]

20. Dallaire-Dufresne, S.; Tanaka, K.H.; Trudel, M.V.; Lafaille, A.; Charette, S.J. Virulence, genomic features, and plasticity of Aeromonas salmonicida subsp. salmonicida, the causative agent of fish furunculosis. Vet. Microbiol. 2014, 169, 1-7. [CrossRef]

21. Altmann, S.; Korytář, T.; Kaczmarzyk, D.; Nipkow, M.; Kühn, C.; Goldammer, T.; Rebl, A. Toll-like receptors in maraena whitefish: Evolutionary relationship among salmonid fishes and patterns of response to Aeromonas salmonicida. Fish Shellfish Immunol. 2016, 54, 391-401. [CrossRef] 
22. Cao, Y.; Wang, D.; Li, S.; Zhao, J.; Xu, L.; Liu, H.; Lu, T.; Mou, Z. A transcriptome analysis focusing on splenic immune-related mciroRNAs of rainbow trout upon Aeromonas salmonicida subsp. salmonicida infection. Fish Shellfish Immunol. 2019, 91, 350-357. [CrossRef]

23. Miest, J.J.; Falco, A.; Pionnier, N.P.M.; Frost, P.; Irnazarow, I.; Williams, G.T.; Hoole, D. The influence of dietary $\beta$-glucan, PAMP exposure and Aeromonas salmonicida on apoptosis modulation in common carp (Cyprinus carpio). Fish Shellfish Immunol. 2012, 33, 846-856. [CrossRef]

24. Soto-Dávila, M.; Hossain, A.; Chakraborty, S.; Rise, M.L.; Santander, J. Aeromonas salmonicida subsp. Salmonicida Early infection and immune response of atlantic cod (Gadus morhua L.) primary macrophages. Front. Immunol. 2019, 10, 1237. [CrossRef] [PubMed]

25. Boyd, J.; Williams, J.; Curtis, B.; Kozera, C.; Singh, R.; Reith, M. Three small, cryptic plasmids from Aeromonas salmonicida subsp. salmonicida A449. Plasmid 2003, 50, 131-144. [CrossRef]

26. Burr, S.E.; Pugovkin, D.; Wahli, T.; Segner, H.; Frey, J. Attenuated virulence of an Aeromonas salmonicida subsp. salmonicida type III secretion mutant in a rainbow trout model. Microbiology 2005, 151, 2111-2118. [CrossRef] [PubMed]

27. Mulder, I.E.; Wadsworth, S.; Secombes, C.J. Cytokine expression in the intestine of rainbow trout (Oncorhynchus mykiss) during infection with Aeromonas salmonicida. Fish Shellfish Immunol. 2007, 23, 747-759. [CrossRef]

28. Ji, L.; Fu, S.; Sun, G.; Li, X.; Liu, Y. Dietary $\beta$-glucan modulate haematological parameters, cytokines and gene expression in TLR and ERK pathways of rainbow trout (Oncorhynchus mykiss) during infection by Aeromonas salmonicida. Aquac. Res. 2020, 51, 906-917. [CrossRef]

29. Komatsu, K.; Tsutsui, S.; Hino, K.; Araki, K.; Yoshiura, Y.; Yamamoto, A.; Nakamura, O.; Watanabe, T. Expression profiles of cytokines released in intestinal epithelial cells of the rainbow trout, Oncorhynchus mykiss, in response to bacterial infection. Dev. Comp. Immunol. 2009, 33, 499-506. [CrossRef]

30. Soleto, I.; Morel, E.; Muñoz-Atienza, E.; Díaz-Rosales, P.; Tafalla, C. Aeromonas salmonicida activates rainbow trout IgM+ B cells signalling through Toll like receptors. Sci. Rep. 2020, 10, 16810. [CrossRef]

31. Korytář, T.; Jaros, J.; Verleih, M.; Rebl, A.; Kotterba, G.; Kühn, C.; Goldammer, T.; Köllner, B. Novel insights into the peritoneal inflammation of rainbow trout (Oncorhynchus mykiss). Fish Shellfish Immunol. 2013, 35, 1192-1199. [CrossRef]

32. Origgi, F.C.; Benedicenti, O.; Segner, H.; Sattler, U.; Wahli, T.; Frey, J. Aeromonas salmonicida type III secretion system-effectorsmediated immune suppression in rainbow trout (Oncorhynchus mykiss). Fish Shellfish Immunol. 2017, 60, 334-345. [CrossRef]

33. Liu, P.F.; Du, Y.; Meng, L.; Li, X.; Yang, D.; Liu, Y. Phosphoproteomic analyses of kidneys of Atlantic salmon infected with Aeromonas salmonicida. Sci. Rep. 2019, 9, 2101. [CrossRef]

34. Liu, P.F.; Du, Y.; Meng, L.; Li, X.; Liu, Y. Metabolic profiling in kidneys of Atlantic salmon infected with Aeromonas salmonicida based on 1H NMR. Fish Shellfish Immunol. 2016, 58, 292-301. [CrossRef] [PubMed]

35. Long, M.; Zhao, J.; Li, T.; Tafalla, C.; Zhang, Q.; Wang, X.; Gong, X.; Shen, Z.; Li, A. Transcriptomic and proteomic analyses of splenic immune mechanisms of rainbow trout (Oncorhynchus mykiss) infected by Aeromonas salmonicida subsp. salmonicida. J. Proteom. 2015, 122, 41-54. [CrossRef] [PubMed]

36. Curtis, L.R.; Bravo, C.F.; Bayne, C.J.; Tilton, F.; Arkoosh, M.R.; Lambertini, E.; Loge, F.J.; Collier, T.K.; Meador, J.P.; Tilton, S.C Transcriptional changes in innate immunity genes in head kidneys from Aeromonas salmonicida-challenged rainbow trout fed a mixture of polycyclic aromatic hydrocarbons. Ecotoxicol. Environ. Saf. 2017, 142, 157-163. [CrossRef]

37. Liu, P.F.; Du, Y.; Meng, L.; Li, X.; Liu, Y. Proteomic analysis in kidneys of Atlantic salmon infected with Aeromonas salmonicida by iTRAQ. Dev. Comp. Immunol. 2017, 72, 140-153. [CrossRef] [PubMed]

38. Marana, M.H.; Karami, A.M.; Ødegård, J.; Zuo, S.; Jaafar, R.M.; Mathiessen, H.; von Gersdorff Jørgensen, L.; Kania, P.W.; Dalsgaard, I.; Nielsen, T.; et al. Whole-genome association study searching for QTL for Aeromonas salmonicida resistance in rainbow trout. Sci. Rep. 2021, 11, 17857. [CrossRef] [PubMed]

39. Panula, P.; Sallinen, V.; Sundvik, M.; Kolehmainen, J.; Torkko, V.; Tiittula, A.; Moshnyakov, M.; Podlasz, P. Modulatory neurotransmitter systems and behavior: Towards zebrafish models of neurodegenerative diseases. Zebrafish 2006, 3, $235-247$. [CrossRef]

40. Quan, N.; Banks, W.A. Brain-immune communication pathways. Brain. Behav. Immun. 2007, 21, 727-735. [CrossRef]

41. Kipnis, J.; Filiano, A.J. Neuroimmunology in 2017: The central nervous system: Privileged by immune connections. Nat. Rev. Immunol. 2018, 18, 83-84. [CrossRef]

42. Rummel, C. Inflammatory transcription factors as activation markers and functional readouts in immune-to-brain communication. Brain. Behav. Immun. 2016, 54, 1-14. [CrossRef]

43. D'Mello, C.; Le, T.; Swain, M.G. Cerebral microglia recruit monocytes into the brain in response to tumor necrosis factora signaling during peripheral organ inflammation. J. Neurosci. 2009, 29, 2089-2102. [CrossRef]

44. Al-Obaidi, M.M.J.; Desa, M.N.M. Mechanisms of Blood Brain Barrier Disruption by Different Types of Bacteria, and Bacterial-Host Interactions Facilitate the Bacterial Pathogen Invading the Brain. Cell. Mol. Neurobiol. 2018, 38, 1349-1368. [CrossRef] [PubMed]

45. Baldissera, M.D.; Souza, C.F.; Santos, R.C.V.; Baldisserotto, B. Blood-brain barrier breakdown and myeloperoxidase activity in silver catfish experimentally infected with Pseudomonas aeruginosa. J. Fish Dis. 2018, 41, 209-213. [CrossRef] [PubMed]

46. Alzaid, A.; Castro, R.; Wang, T.; Secombes, C.J.; Boudinot, P.; Macqueen, D.J.; Martin, S.A.M. Cross talk between growth and immunity: Coupling of the igf axis to conserved cytokine pathways in rainbow trout. Endocrinology 2016, 157, 1942-1955. [CrossRef] [PubMed] 
47. MacQueen, D.J.; Garcia De La Serrana, D.; Johnston, I.A. Evolution of ancient functions in the vertebrate insulin-like growth factor system uncovered by study of duplicated salmonid fish genomes. Mol. Biol. Evol. 2013, 30, 1060-1076. [CrossRef]

48. Lin, H.; Lee, E.; Hestir, K.; Leo, C.; Huang, M.; Bosch, E.; Halenbeck, R.; Wu, G.; Zhou, A.; Behrens, D.; et al. Discovery of a cytokine and its receptor by functional screening of the extracellular proteome. Science 2008, 320, 807-811. [CrossRef]

49. Ma, X.; Lin, W.Y.; Chen, Y.; Stawicki, S.; Mukhyala, K.; Wu, Y.; Martin, F.; Bazan, J.F.; Starovasnik, M.A. Structural basis for the dual recognition of helical cytokines IL-34 and CSF-1 by CSF-1R. Structure 2012, 20, 676-687. [CrossRef]

50. Chen, Q.; Lu, X.J.; Li, M.Y.; Chen, J. Molecular cloning, pathologically-correlated expression and functional characterization of the colony stimulating factor 1 receptor (CSF-1R) gene from a teleost, Plecoglossus altivelis. Dong Wu Xue Yan Jiu Zool Res. 2016, 37, 96-102. [CrossRef]

51. Dai, X.M.; Ryan, G.R.; Hapel, A.J.; Dominguez, M.G.; Russell, R.G.; Kapp, S.; Sylvestre, V.; Stanley, E.R. Targeted disruption of the mouse colony-stimulating factor 1 receptor gene results in osteopetrosis, mononuclear phagocyte deficiency, increased primitive progenitor cell frequencies, and reproductive defects. Blood 2002, 99, 111-120. [CrossRef]

52. Droin, N.; Solary, E. Editorial: CSF1R, CSF-1, and IL-34, a "ménage à trois" conserved across vertebrates. J. Leukoc. Biol. 2010, 87, 745-747. [CrossRef]

53. Lee, C.G.L.; Jenkins, N.A.; Gilbert, D.J.; Copeland, N.G.; O'Brien, W.E. Cloning and analysis of gene regulation of a novel LPS-inducible cDNA. Immunogenetics 1995, 41, 263-270. [CrossRef]

54. Michelucci, A.; Cordes, T.; Ghelfi, J.; Pailot, A.; Reiling, N.; Goldmann, O.; Binz, T.; Wegner, A.; Tallam, A.; Rausell, A.; et al Immune-responsive gene 1 protein links metabolism to immunity by catalyzing itaconic acid production. Proc. Natl. Acad. Sci. USA 2013, 110, 7820-7825. [CrossRef] [PubMed]

55. Wu, R.; Chen, F.; Wang, N.; Tang, D.; Kang, R. ACOD1 in immunometabolism and disease. Cell. Mol. Immunol. 2020, 17, 822-833. [CrossRef] [PubMed]

56. Cordes, T.; Wallace, M.; Michelucci, A.; Divakaruni, A.S.; Sapcariu, S.C.; Sousa, C.; Koseki, H.; Cabrales, P.; Murphy, A.N.; Hiller, $\mathrm{K}$; ; et al. Immunoresponsive gene 1 and itaconate inhibit succinate dehydrogenase to modulate intracellular succinate levels. $J$. Biol. Chem. 2016, 291, 14274-14284. [CrossRef] [PubMed]

57. Wentzel, A.S.; Janssen, J.J.E.; de Boer, V.C.J.; van Veen, W.G.; Forlenza, M.; Wiegertjes, G.F. Fish Macrophages Show Distinct Metabolic Signatures Upon Polarization. Front. Immunol. 2020, 11, 152. [CrossRef]

58. Ryan, S.O.; Cobb, B.A. Roles for major histocompatibility complex glycosylation in immune function. Semin. Immunopathol. 2012, 34, 425-441. [CrossRef]

59. Janeway, C.A., Jr.; Travers, P.; Walport, M. Immunobiology: The Immune System in Health and Disease: The major histocompatibility complex and its functions. Immunobiol. Immune Syst. Health Dis. 2001. Available online: https://www.ncbi.nlm.nih.gov/ books / NBK27156/ (accessed on 1 December 2021).

60. Hewitt, E.W. The MHC class I antigen presentation pathway: Strategies for viral immune evasion. Immunology 2003, 110, 163-169. [CrossRef]

61. Delamarre, L.; Holcombe, H.; Mellman, I. Presentation of exogenous antigens on major histocompatibility complex (MHC) class I and MHC class II molecules is differentially regulated during dendritic cell maturation. J. Exp. Med. 2003, 198, 111-122. [CrossRef]

62. Rock, K.L.; York, I.A.; Saric, T.; Goldberg, A.L. Protein degradation and the generation of MHC class I-presented peptides. Adv. Immunol. 2002, 80, 1-70. [CrossRef]

63. Wieczorek, M.; Abualrous, E.T.; Sticht, J.; Álvaro-Benito, M.; Stolzenberg, S.; Noé, F.; Freund, C. Major histocompatibility complex (MHC) class I and MHC class II proteins: Conformational plasticity in antigen presentation. Front. Immunol. 2017, 8, 292. [CrossRef]

64. Kjøglum, S.; Larsen, S.; Bakke, H.G.; Grimholt, U. The effect of specific MHC class I and class II combinations on resistance to furunculosis in Atlantic salmon (Salmo salar). Scand. J. Immunol. 2008, 67, 160-168. [CrossRef]

65. Kjøglum, S.; Larsen, S.; Bakke, H.G.; Grimholt, U. How specific MHC class I and class II combinations affect disease resistance against infectious salmon anaemia in Atlantic salmon (Salmo salar). Fish Shellfish Immunol. 2006, 21, 431-441. [CrossRef] [PubMed]

66. Yewdell, J.W.; Norbury, C.C.; Bennink, J.R. Mechanisms of Exogenous Antigen Presentation by MHC Class I Molecules In Vitro and In Vivo: Implications for Generating CD8+ T Cell Responses to Infectious Agents, Tumors, Transplants, and Vaccines. Adv. Immunol. 1999, 73, 1-77, ISBN 0065-2776. [PubMed]

67. Croisetière, S.; Tarte, P.D.; Bernatchez, L.; Belhumeur, P. Identification of MHC class II $\beta$ resistance/susceptibility alleles to Aeromonas salmonicida in brook charr (Salvelinus fontinalis). Mol. Immunol. 2008, 45, 3107-3116. [CrossRef] [PubMed]

68. Yi, Y.S.; Son, Y.J.; Ryou, C.; Sung, G.H.; Kim, J.H.; Cho, J.Y. Functional roles of Syk in macrophage-mediated inflammatory responses. Mediators Inflamm. 2014, 2014, 270302. [CrossRef] [PubMed]

69. Shastri, A.; Bonifati, D.M.; Kishore, U. Innate immunity and neuroinflammation. Mediators Inflamm. 2013, 2013, 342931. [CrossRef] [PubMed]

70. Galea, I.; Bechmann, I.; Perry, V.H. What is immune privilege (not)? Trends Immunol. 2007, 28, 12-18. [CrossRef]

71. Huang, C.; Irwin, M.G.; Wong, G.T.C.; Chang, R.C.C. Evidence of the impact of systemic inflammation on neuroinflammation from a non-bacterial endotoxin animal model. J. Neuroinflamm. 2018, 15, 147. [CrossRef]

72. Hoogland, I.C.M.; Houbolt, C.; van Westerloo, D.J.; van Gool, W.A.; van de Beek, D. Systemic inflammation and microglial activation: Systematic review of animal experiments. J. Neuroinflamm. 2015, 12, 114. [CrossRef] 
73. Zotova, E.; Bharambe, V.; Cheaveau, M.; Morgan, W.; Holmes, C.; Harris, S.; Neal, J.W.; Love, S.; Nicoll, J.A.R.; Boche, D. Inflammatory components in human Alzheimer's disease and after active amyloid- $\beta 42$ immunization. Brain 2013, 136, $2677-2696$. [CrossRef]

74. Ransohoff, R.M. How neuroinflammation contributes to neurodegeneration. Science 2016, 353, 777-783. [CrossRef]

75. Capuron, L.; Miller, A.H. Immune system to brain signaling: Neuropsychopharmacological implications. Pharmacol. Ther. 2011, 130, 226-238. [CrossRef] [PubMed]

76. Dowlati, Y.; Herrmann, N.; Swardfager, W.; Liu, H.; Sham, L.; Reim, E.K.; Lanctôt, K.L. A Meta-Analysis of Cytokines in Major Depression. Biol. Psychiatry 2010, 67, 446-457. [CrossRef] [PubMed]

77. Howren, M.B.; Lamkin, D.M.; Suls, J. Associations of depression with c-reactive protein, IL-1, and IL-6: A meta-analysis. Psychosom. Med. 2009, 71, 171-186. [CrossRef] [PubMed]

78. Kumar, V. Toll-like receptors in the pathogenesis of neuroinflammation. J. Neuroimmunol. 2019, 332, 16-30. [CrossRef] [PubMed]

79. Lim, K.H.; Staudt, L.M. Toll-Like receptor signaling. Cold Spring Harb. Perspect. Biol. 2013, 5. [CrossRef] [PubMed]

80. Kawasaki, T.; Kawai, T. Toll-like receptor signaling pathways. Front. Immunol. 2014, 5, 461. [CrossRef] [PubMed]

81. Ji, L.; Sun, G.; Li, X.; Liu, Y. Comparative transcriptome analysis reveals the mechanism of $\beta$-glucan in protecting rainbow trout (Oncorhynchus mykiss) from Aeromonas salmonicida infection. Fish Shellfish Immunol. 2020, 98, 87-99. [CrossRef]

82. Rebl, A.; Siegl, E.; Köllner, B.; Fischer, U.; Seyfert, H.M. Characterization of twin toll-like receptors from rainbow trout (Oncorhynchus mykiss): Evolutionary relationship and induced expression by Aeromonas salmonicida salmonicida. Dev. Comp. Immunol. 2007, 31, 499-510. [CrossRef]

83. Besedovsky, H.O.; del Rey, A. Immune-neuro-endocrine interactions: Facts and hypotheses. Endocr. Rev. 1996, 17, 64-102. [CrossRef]

84. Harris, J.; Bird, D.J. Modulation of the fish immune system by hormones. Vet. Immunol. Immunopathol. 2000, 77, 163-176. [CrossRef]

85. Tort, L. Stress and immune modulation in fish. Dev. Comp. Immunol. 2011, 35, 1366-1375. [CrossRef] [PubMed]

86. Del Rey, A.; Besedovsky, H.O. Immune-Neuro-Endocrine Reflexes, Circuits, and Networks: Physiologic and Evolutionary Implications. Front. Horm. Res. 2017, 48, 1-18. [CrossRef] [PubMed]

87. Wensveen, F.M.; Šestan, M.; Turk Wensveen, T.; Polić, B. 'Beauty and the beast' in infection: How immune-endocrine interactions regulate systemic metabolism in the context of infection. Eur. J. Immunol. 2019, 49, 982-995. [CrossRef] [PubMed]

88. Milla, S.; Depiereux, S.; Kestemont, P. The effects of estrogenic and androgenic endocrine disruptors on the immune system of fish: A review. Ecotoxicology 2011, 20, 305-319. [CrossRef] [PubMed]

89. Cabas, I.; Chaves-Pozo, E.; Mulero, V.; García-Ayala, A. Role of estrogens in fish immunity with special emphasis on GPER1. Dev. Comp. Immunol. 2018, 89, 102-110. [CrossRef] [PubMed]

90. Geissmann, F.; Manz, M.G.; Jung, S.; Sieweke, M.H.; Merad, M.; Ley, K. Development of monocytes, macrophages, and dendritic cells. Science 2010, 327, 656-661. [CrossRef]

91. Hume, D.A.; Ross, I.L.; Himes, S.R.; Sasmono, R.T.; Wells, C.A.; Ravasi, T. The mononuclear phagocyte system revisited. J. Leukoc. Biol. 2002, 72, 621-627. [CrossRef]

92. Rettenmier, C.W.; Roussel, M.F. Differential processing of colony-stimulating factor 1 precursors encoded by two human cDNAs. Mol. Cell. Biol. 1988, 8, 5026-5034. [CrossRef]

93. Wu, Z.; Harne, R.; Chintoan-Uta, C.; Hu, T.J.; Wallace, R.; MacCallum, A.; Stevens, M.P.; Kaiser, P.; Balic, A.; Hume, D.A. Regulation and function of macrophage colony-stimulating factor (CSF1) in the chicken immune system. Dev. Comp. Immunol. 2020, 105, 103586. [CrossRef]

94. Hanington, P.C.; Wang, T.; Secombes, C.J.; Belosevic, M. Growth factors of lower vertebrates: Characterization of goldfish (Carassius auratus L.) macrophage colony-stimulating factor-1. J. Biol. Chem. 2007, 282, 31865-31872. [CrossRef]

95. Wang, T.; Kono, T.; Monte, M.M.; Kuse, H.; Costa, M.M.; Korenaga, H.; Maehr, T.; Husain, M.; Sakai, M.; Secombes, C.J. Identification of IL-34 in teleost fish: Differential expression of rainbow trout IL-34, MCSF1 and MCSF2, ligands of the MCSF receptor. Mol. Immunol. 2013, 53, 398-409. [CrossRef] [PubMed]

96. Shen, H.Y.; Zhou, Y.; Zhou, Q.J.; Li, M.Y.; Chen, J. Mudskipper interleukin-34 modulates the functions of monocytes/macrophages via the colony-stimulating factor-1 receptor 1. Zool. Res. 2020, 41, 123-137. [CrossRef] [PubMed]

97. Berthelot, C.; Brunet, F.; Chalopin, D.; Juanchich, A.; Bernard, M.; Noël, B.; Bento, P.; Da Silva, C.; Labadie, K.; Alberti, A.; et al. The rainbow trout genome provides novel insights into evolution after whole-genome duplication in vertebrates. Nat. Commun. 2014, 5, 3657. [CrossRef] [PubMed]

98. Gu, H.; Wang, B.; He, J.; Hu, Y. Macrophage colony stimulating factor (MCSF) of Japanese flounder (Paralichthys olivaceus): Immunoregulatory property, anti-infectious function, and interaction with MCSF receptor. Dev. Comp. Immunol. 2021, 116, 103920. [CrossRef] [PubMed]

99. Mo, Z.Q.; Li, Y.W.; Zhou, L.; Li, A.X.; Luo, X.C.; Dan, X.M. Grouper (Epinephelus coioides) IL-34/MCSF2 and MCSFR1/MCSFR2 were involved in mononuclear phagocytes activation against Cryptocaryon irritans infection. Fish Shellfish Immunol. 2015, 43, 142-149. [CrossRef] [PubMed]

100. Zeng, C.; Hou, Z.S.; Zhao, H.K.; Xin, Y.R.; Liu, M.Q.; Yang, X.D.; Wen, H.S.; Li, J.F. Identification and characterization of caspases genes in rainbow trout (Oncorhynchus mykiss) and their expression profiles after Aeromonas salmonicida and Vibrio anguillarum infection. Dev. Comp. Immunol. 2021, 118, 103987. [CrossRef] 
101. Bolger, A.M.; Lohse, M.; Usadel, B. Trimmomatic: A flexible trimmer for Illumina sequence data. Bioinformatics 2014, 30, 2114-2120. [CrossRef]

102. Kim, D.; Langmead, B.; Salzberg, S.L. HISAT: A fast spliced aligner with low memory requirements. Nat. Methods 2015, 12, 357-360. [CrossRef]

103. Love, M.I.; Huber, W.; Anders, S. Moderated estimation of fold change and dispersion for RNA-seq data with DESeq2. Genome Biol. 2014, 15, 550. [CrossRef]

104. Anders, S.; Huber, W. Differential expression of RNA-Seq data at the gene level-The DESeq package. Heidelberg, Ger. Eur. Mol. Biol. Lab. 2012, 10, f1000research.

105. Livak, K.J.; Schmittgen, T.D. Analysis of relative gene expression data using real-time quantitative PCR and the $2^{-\Delta \Delta C T}$ method. Methods 2001, 25, 402-408. [CrossRef] [PubMed]

106. Zhao, H.; Soufan, O.; Xia, J.; Tang, R.; Li, L.; Li, D. Transcriptome and physiological analysis reveal alterations in muscle metabolisms and immune responses of grass carp (Ctenopharyngodon idellus) cultured at different stocking densities. Aquaculture 2019, 503, 186-197. [CrossRef]

107. Mouton, A.J.; Ma, Y.; Rivera Gonzalez, O.J.; Daseke, M.J.; Flynn, E.R.; Freeman, T.C.; Garrett, M.R.; DeLeon-Pennell, K.Y.; Lindsey, M.L. Fibroblast polarization over the myocardial infarction time continuum shifts roles from inflammation to angiogenesis. Basic Res. Cardiol. 2019, 114, 1-16. [CrossRef] [PubMed]

108. Chong, J.; Wishart, D.S.; Xia, J. Using MetaboAnalyst 4.0 for Comprehensive and Integrative Metabolomics Data Analysis. Curr. Protoc. Bioinform. 2019, 68, 1-128. [CrossRef] 